\title{
Distinct eicosanoid profile in exhaled breath condensates from granulomatosis with polyangiitis (Wegener's) patients
}

\author{
Wojciech Szczeklik • Marek Sanak • Barbara Sokołowska • \\ Bogdan Jakiela • Jan Sznajd • Anna Gielicz • Marek Kaszuba • \\ Agata Sawina $\cdot$ Jacek Musial
}

Received: 13 January 2013 / Revised: 10 May 2013 / Accepted: 14 May 2013 /Published online: 2 June 2013

(C) The Author(s) 2013. This article is published with open access at Springerlink.com

\section{Introduction}

Granulomatosis with polyangiitis (GPA, Wegener's) is a systemic vasculitis affecting mostly small vessels, typically involving the upper respiratory tract, lungs, and kidneys. Together with microscopic polyangiitis, eosinophilic granulomatosis with polyangiitis (Churg-Strauss syndrome), and renal-limited vasculitis, it commonly shows circulating antineutrophil cytoplasmic antibodies (ANCA). As such, it is typically referred to as an ANCA-associated vasculitis [1, 2]. The pathogenesis of GPA has not been fully elucidated, although the interaction between ANCA and neutrophils seems pivotal in initiating and supporting an inflammatory reaction with subsequent cytokine, complement, and endothelium involvement [3]. The hallmark of the respiratory tract pathology is granulomatous inflammation, in which the eicosanoid derivatives play an important role. Clinical diagnostics often requires an invasive approach, i.e., open lung biopsy, bronchoalveolar lavage, or bronchoscopy-guided biopsies. Recently, a noninvasive diagnostic method of the respiratory tract examination was introduced; namely, exhaled breath condensate (EBC) analysis. We have previously described a highly specific increase in 12-lipoxygenase product (12-HETE) in EBC samples of eosinophilic with polyangiitis patients [4]. We wondered if ascertainment of eicosanoid profile in EBC from GPA patients could help in noninvasive diagnostics of GPA.

W. Szczeklik $(\triangle) \cdot$ M. Sanak $\cdot$ B. Sokołowska $\cdot$ B. Jakieła $\cdot$

J. Sznajd · A. Gielicz · M. Kaszuba · A. Sawina · J. Musiał

Department of Medicine, Jagiellonian University

Medical College, ul. Skawińska 8,

31-066 Krakow, Poland

e-mail:wszczeklik@gmail.com
Patients and methods

Patients

We enrolled 27 patients with GPA treated in the Department of Medicine of the University Hospital, Jagiellonian University Medical College. The control group consisted of 30 healthy volunteers recruited from the hospital employees with similar gender distribution. GPA was diagnosed according to the American college of rheumatology criteria, and all patients were c-ANCA positive [5]. The Birmingham vasculitis activity score (BVAS v.3, range $0-63$ points) [6] was used to assess activity of GPA; results above three indicated active disease. All subjects studied gave informed written consent to participate. The study protocol complied with the Helsinki Declaration and was approved by the Jagiellonian University ethics committee.

Exhaled breath condensate collection and analysis

EBC were collected with EcoScreen I Jaeger ${ }^{\circledR}$ condensing chamber (GmbH Hoechberg, Germany) according to the ATS/ERS recommendations [7]. Collected EBC (1-2 ml within $15 \mathrm{~min}$ ) was immediately stored at $-80^{\circ} \mathrm{C}$ until analysis.

High-performance liquid chromatography tandem mass spectrometry (HPLC-MS/MS; Qtrap 4000, Applied Biosystems, Foster City, CA, USA) or gas chromatography-mass spectrometry (GC-MS; Engine 5989B series II Hewlett Packard, Palo Alto, CA, USA) were used for the quantification of substances with a stable isotope dilution method [8]. The detection levels for the eicosanoids (in picograms per milliliter) were as previously described $[8$, 9], and palmitic acid (PA) - abundant in EBC — was used for a correction of dilution factor. Eicosanoids were 
Table 1 Eicosanoid profile in exhaled breath condensate (EBC) of Granulomatosis with polyangiitis patients (Wegener's, GPA) and healthy controls (HC)

Median (25-75 interquartile range) concentration of eicosanoid in EBC are presented as picograms per microgram of palmitic acid (ppm)

$H C$ healthy controls, GPA granulomatosis with polyangiitis (Wegener's), HETE hydroxyeicosatetraenoic acid, $L T$ leukotriene, $P G$ prostaglandin, tetranor$P G E M$ tetranor-prostaglandin E metabolite, $T X$ thromboxane, 6 keto-PGF1 $\alpha$ prostacyclin metabolite, 8 -iso- $P G F_{2 \alpha}$ isoprostane $\mathrm{F}_{2 \alpha}, 9 a, 11 b-P G F_{2} \quad \mathrm{PGD}_{2}$ metabolite

\begin{tabular}{|c|c|c|c|}
\hline & GPA & $\mathrm{HC}$ & $P$ value \\
\hline 5-HETE & $2.69(1.88-3.95)$ & $4.70(3.28-8.54)$ & $<0.001$ \\
\hline 12-HETE & $4.63(3.46-5.99)$ & $5.67(3.57-8.33)$ & NS \\
\hline 15-HETE & $4.35(3.14-6.09)$ & $5.84(3.68-9.78)$ & 0.054 \\
\hline $\mathrm{LTB}_{4}$ & $49.09(20.3-77.3)$ & $16.14(10.73-26.01)$ & $<0.001$ \\
\hline $\mathrm{LTC}_{4}$ & $0.64(0.44-1.41)$ & $2(0.89-4.83)$ & $<0.01$ \\
\hline Trans-LTC $_{4}$ & $39.67(32.62-77.92)$ & $194.4(35.71-296.53)$ & $<0.01$ \\
\hline $\mathrm{LTD}_{4}$ & $1.54(0.84-1.98)$ & $1.89(0.78-3.94)$ & NS \\
\hline $\mathrm{LTE}_{4}$ & $2.37(1.24-3.83)$ & $2.41(1.4-4.32)$ & NS \\
\hline Eoxin $\mathrm{C}_{4}$ & $0.68(0.36-0.91)$ & $1.06(0.58-2.12)$ & $<0.01$ \\
\hline Eoxin $\mathrm{D}_{4}$ & $0.53(0.32-1.46)$ & $1.47(0.92-2.83)$ & $<0.01$ \\
\hline Eoxin $\mathrm{E}_{4}$ & $1.01(0.56-2.04)$ & $8.08(4.86-19.24)$ & $<0.01$ \\
\hline Lipoxin $\mathrm{A}_{4}$ & $0.93(0.47-1.64)$ & $0.72(0.45-1.71)$ & NS \\
\hline 11-dehydro- $\mathrm{TXB}_{2}$ & $13.51(10.37-15.37)$ & $10.0(7.71-12.31)$ & $<0.001$ \\
\hline $\mathrm{PGD}_{2}$ & $2.91(1.46-5.41)$ & $1.89(0.65-3.16)$ & $<0.01$ \\
\hline $9 a, 11 b-P F_{2}$ & $0.28(0.13-0.39)$ & $0.59(0.37-0.87)$ & $<0.001$ \\
\hline $\mathrm{PGE}_{2}$ & $2.04(1.22-3.79)$ & $1.75(0.94-3.49)$ & NS \\
\hline Tetranor-PGEM & $39.67(32.62-77.92)$ & $194.4(35.71-296.53)$ & $<0.01$ \\
\hline 6-keto-PGF $1 \alpha$ & $13.83(10.28-17.84)$ & $15.71(11.54-20.16)$ & NS \\
\hline $\mathrm{PGF}_{2 \alpha}$ & $0.89(0.17-2.23)$ & $0.69(0.42-1.41)$ & NS \\
\hline 8 -iso-PGF $2 \alpha$ & $0.48(0.36-0.73)$ & $0.5(0.33-0.84)$ & NS \\
\hline
\end{tabular}

therefore expressed in picograms per microgram of PA (in parts per million).

Lung function tests

Lung function tests were performed using the protocols recommended by ATS/ERS guidelines [10]. Forced expiratory volume in $1 \mathrm{~s}\left(\mathrm{FEV}_{1}\right)$ and vital capacity $(\mathrm{FVC})$ were expressed as a percentage of predicted value.

Statistical analysis

Statistical analysis was performed using Statistica software (StatSoft, Inc., 2011). Data are presented as the median with interquartile range. After ascertaining the normal distribution, the comparisons of eicosanoids between the two groups were done using the Student's $t$ test, Welch's test, or by Mann-Whitney $U$ test. Correlation analyses were performed using Pearson's test or Spearman's test as appropriate, with respect to data distribution. $P$ values less than 0.05 were considered as statistically significant.

\section{Results}

The healthy controls $(\mathrm{HC})$ were gender matched with the GPA patients; however, they were younger (41.5 \pm [26-53] for $\mathrm{HC}$ and $58 \pm[46-61]$ for GPA; $p=0.041)$. In the GPA
Fig. 1 Values of lipoxygenase and cyclooxygenase pathways

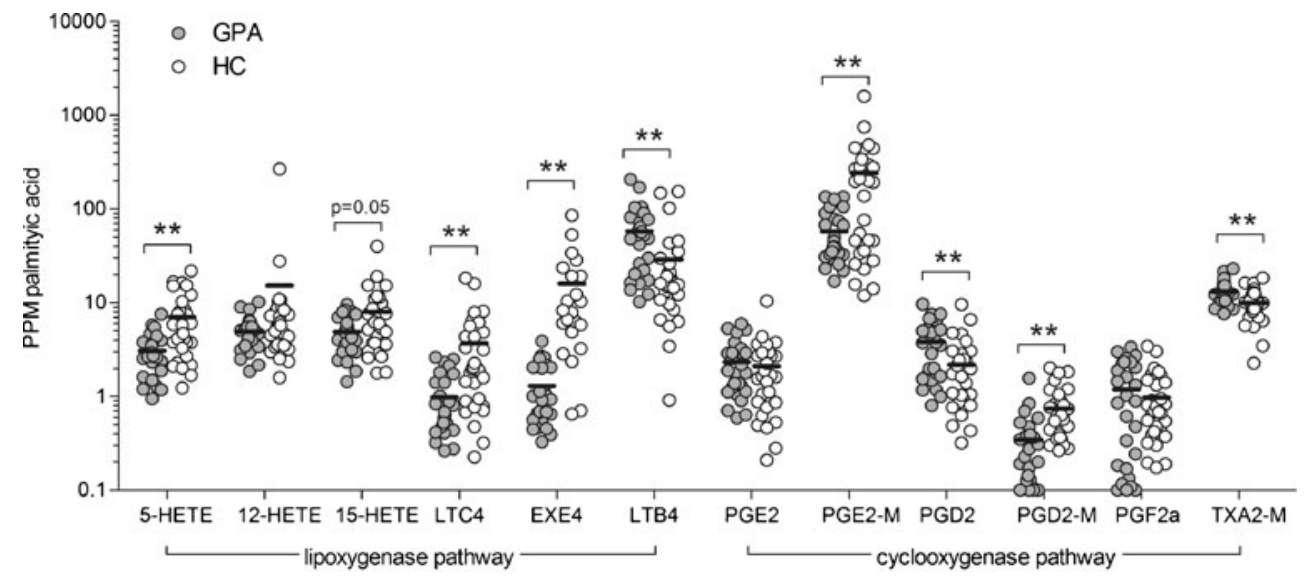


group, there were 11 (40.7\%) women and $16(59.3 \%)$ men. All patients in their course of the disease had positive cANCA; and during the study, it was positive in 15/27 patients $(55.5 \%)$. The mean BVAS was $1(0-7)$, and $18 / 27$ patients $(66 \%)$ were in disease remission. Twentyone $(77.8 \%)$ patients were treated with corticosteroids, with the mean dose of $7 \mathrm{mg}$ [4-16] daily of methylprednisolone, and $17(63 \%)$ were on additional immunosuppressive therapy, mainly cyclophosphamide. During the course of the disease, 23/27 patients $(85 \%)$ had documented lung involvement, whereas in the time of the study, 11/27 (41\%) patients had either characteristic for the disease lung changes detected in x-ray or in computed tomography. Mean $\mathrm{FEV}_{1} \%$ was 87 (79.9-96.2) and FVC 90.2 (82.8101). Eleven patients ( $41 \%$ ) were either present of previous smokers similarly to the HC.

Significant differences in the EBC eicosanoid profile between GPA group and $\mathrm{HC}$ were observed. In the GPA group, $\mathrm{LTB}_{4}, \mathrm{PGD}_{2}$, and 11-dehydro-TXB 2 were elevated, whereas 5-HETE, $\mathrm{LTC}_{4}$, trans $\mathrm{LTC}_{4}$, eoxins $\left(\mathrm{C}_{4}, \mathrm{D}_{4}, \mathrm{E}_{4}\right), 9_{\alpha}, 11_{\beta}$ $\mathrm{PGF} 2 \alpha$, and tetranor-PGE-M were decreased. All measured eicosanoids values are shown in Table 1 and Fig. 1.

No correlation between clinical manifestation of the GPA presentation, lung abnormalities, dose of oral corticosteroids, BVAS score, or remission/exacerbation period and EBC eicosanoids was observed.

\section{Discussion}

In the current study, we show that the profile of eicosanoids measured in the EBC from GPA patients differs substantially from healthy controls. We observed increase in the concentration of $\mathrm{LTB}_{4}$ and $\mathrm{PGD}_{2}$ and concomitant decrease in eoxins, cysteinyl leukotrienes, and $\mathrm{PGE}_{2}$ metabolite in EBC sampled from GPA patients. A significant elevation of leukotriene $\mathrm{B}_{4}$, a 5-lipoxygenase (5-LO) product, was reported to be associated with the presence of anti-PR3 autoantibodies in GPA [11]. $\mathrm{LTB}_{4}$ is a potent chemoattractant and activator of neutrophils, which produce $\mathrm{LTB}_{4}$ by themselves or by activation of macrophages/monocytes [12]. Interestingly, an induction of the 5LO pathway was not followed by an increase of other mediators, e.g., 5-HETE, cysteinyl leukotrienes, and eoxins. It may be explained by a lack of expression of leukotriene- $\mathrm{C}_{4}$ synthase by mature neutrophils and activation-dependent translocation of 5-LO and subsequent switch in substrate specificity [13]. $\mathrm{LTB}_{4}$ is an autocrine positive feedback signal for neutrophils, which is accompanied by a selective increase of some cyclooxygenase products: 11-dehydro-thromboxane $\mathrm{B}_{2}$ and prostaglandin $\mathrm{D}_{2}$ - both with known effects on the bronchi and vasculature. The latter $\left(\mathrm{PGD}_{2}\right)$ is a potent antiinflammatory mediator, and some studies suggest that it plays a major role as a signaling molecule between alveolar/epithelial cells and infiltrating neutrophils, resulting in inhibition of the inflammatory process (e.g., in acute lung injury) [14]. It is furthermore probable, as PGDR $\left(\mathrm{PGD}_{2}\right.$ receptor) gene has been found to be upregulated in neutrophils stimulated in vitro with native anti-PR3 autoantibodies [15]. However, this overproduction of proinflammatory prostanoids was not counterbalanced by $\mathrm{PGE}_{2}$, or its metabolite - tetranor-PGEM, suggesting decreased biosynthetic capacity of $\mathrm{PGE}_{2}$ in prostaglandin pathway. Our findings support the hypothesis of a specific type of neutrophil ANCA priming, which results in a distinct pattern of proinflammatory lipid mediators in GPA [16].

No differences in the eicosanoid profile were noted between the active and remission phase of the disease. In our opinion, this could be due to the fact the most of the patients were on systemic corticosteroids and additional immunosuppressive therapy. Other factor that may influence this lack of correlation between the disease activity and eicosanoid profile is that lung assessment in GPA patients is based on radiographic x-ray or computed tomography findings that may not reflect the ongoing inflammatory process in the respiratory tract.

We are aware that this is just a preliminary study, and that it has several limitations, such as the sample size of the studied group. Also, due to low levels of measured eicosanoids, that so far need a sophisticated and not widely available analytical platform based on mass spectrometry, these findings may not find its way to clinical practice in the nearest future.

Nevertheless, sampling of a noninvasive material (EBC) of the bronchial epithelial lining fluid in GPA patients gives insight into a specific pattern of arachidonic acid pathway metabolites reflecting the presence of primed neutrophils. These findings may help to better understand the inflammatory process in the GPA patients; and maybe, together with the circulating ANCA status, could discriminate for GPA and perhaps guide future therapies.

Acknowledgments The authors would like to thank Jagoda Kumik and Hanna Plutecka for their invaluable technical support.

Acknowledgments of funding This work was supported by a grant from the Polish Ministry of Science and Higher Education-Iuventus Plus 2012

\section{Disclosures None.}

Open Access This article is distributed under the terms of the Creative Commons Attribution License which permits any use, distribution, and reproduction in any medium, provided the original author(s) and the source are credited.

\section{References}

1. Chen M, Kallenberg CG (2010) ANCA-associated vasculitides: advances in pathogenesis and treatment. Nat Rev Rheumatol 6(11):653-664. doi:10.1038/nrrheum.2010.158 
2. Szczeklik W, Jakiela B, Adamek D, Musial J (2013) Cutting edge issues in the Churg-Strauss syndrome. Clin Rev Allergy Immunol 44(1):39-50. doi:10.1007/s12016-011-8266-y

3. Schilder AM (2010) Wegener's granulomatosis vasculitis and granuloma. Autoimmun Rev 9(7):483-487. doi:10.1016/j.autrev.2010.02.006

4. Szczeklik W, Sanak M, Mastalerz L, Sokolowska BM, Gielicz A, Soja J, Kumik J, Musial J, Szczeklik A (2012) 12-hydroxyeicosatetraenoic acid (12-HETE): a biomarker of Churg-Strauss syndrome. Clinical and experimental allergy. J Br Soc Allergy Clin Immunol 42(4):513-522. doi:10.1111/j.1365-2222.2011.03943.x

5. Leavitt RY, Fauci AS, Bloch DA, Michel BA, Hunder GG, Arend WP, Calabrese LH, Fries JF, Lie JT, Lightfoot RW Jr et al (1990) The American college of rheumatology 1990 criteria for the classification of Wegener's granulomatosis. Arthritis Rheum 33(8):1101-1107

6. Suppiah R, Mukhtyar C, Flossmann O, Alberici F, Baslund B, Batra R, Brown D, Holle J, Hruskova Z, Jayne DR, Judge A, Little MA, Palmisano A, Stegeman C, Tesar V, Vaglio A, Westman K, Luqmani R (2010) A cross-sectional study of the Birmingham vasculitis activity score version 3 in systemic vasculitis. Rheumatology. doi:10.1093/rheumatology/keq400, Oxford

7. Horvath IdJ, J.C (eds) (2010) Exhaled Biomarkers, vol 49. European Respiratory monograph, 1 edn. European Respiratory Society

8. Sanak M, Gielicz A, Nagraba K, Kaszuba M, Kumik J, Szczeklik A (2010) Targeted eicosanoids lipidomics of exhaled breath condensate in healthy subjects. J Chromatogr B Analyt Technol Biomed Life Sci 878(21):1796-1800. doi:10.1016/j.jchromb.2010.05.012

9. Sanak M, Gielicz A, Bochenek G, Kaszuba M, NizankowskaMogilnicka E, Szczeklik A (2011) Targeted eicosanoid lipidomics of exhaled breath condensate provide a distinct pattern in the aspirin-intolerant asthma phenotype. J Allergy Clin Immunol. doi:10.1016/j.jaci.2010.12.1108

10. Brusasco V, Crapo R, Viegi G (2005) Coming together: the ATS/ ERS consensus on clinical pulmonary function testing. Eur Respir J 26(1):1-2. doi:10.1183/09031936.05.00034205
11. Grimminger F, Hattar K, Papavassilis C, Temmesfeld B, Csernok E, Gross WL, Seeger W, Sibelius U (1996) Neutrophil activation by antiproteinase 3 antibodies in Wegener's granulomatosis: role of exogenous arachidonic acid and leukotriene $\mathrm{B}_{4}$ generation. $\mathrm{J}$ Exp Med 184(4):1567-1572

12. Peters-Golden M, Henderson WR Jr (2007) Leukotrienes. N Engl J Med 357(18):1841-1854. doi:10.1056/NEJMra071371

13. Hill E, Maclouf J, Murphy RC, Henson PM (1992) Reversible membrane association of neutrophil 5-lipoxygenase is accompanied by retention of activity and a change in substrate specificity. $\mathrm{J}$ Biol Chem 267(31):22048-22053

14. Murata T, Aritake K, Tsubosaka Y, Maruyama T, Nakagawa T, Hori M, Hirai H, Nakamura M, Narumiya S, Urade Y, Ozaki H (2013) Antiinflammatory role of $\mathrm{PGD}_{2}$ in acute lung inflammation and therapeutic application of its signal enhancement. Proc Natl Acad Sci USA 110(13):5205-5210. doi:10.1073/pnas.1218091110

15. Surmiak M, Kaczor M, Sanak M (2012) Expression profile of proinflammatory genes in neutrophil-enriched granulocytes stimulated with native anti-PR3 autoantibodies. J Physiol Pharmacol 63(3):249-256, an official journal of the Polish Physiological Society

16. Hattar K, Bickenbach A, Csernok E, Rosseau S, Grandel U, Seeger W, Grimminger F, Sibelius U (2002) Wegener's granulomatosis: antiproteinase 3 antibodies induce monocyte cytokine and prostanoid release-role of autocrine cell activation. J Leukoc Biol 71(6):996-1004

\section{Key messages}

GPA patients have a specific pattern of eicosanoids measured in exhaled breath condensate 